\title{
Wir freuen uns auf Sie!
}

_ Bald ist es wieder so weit: Am 3. Oktober findet in Leinfelden bei Stuttgart der dritte ergotag statt - ausgerichtet vom Thieme Verlag in Zusammenarbeit mit dem Fachkreis Pädiatrie des DVE. Spannende Themen rund um das Vorschulkind in der Ergotherapie warten auf Sie.

_ Laut Heilmittelbericht des Wissenschaftlichen Instituts der AOK erhalten Kinder am häufigsten an der Schwelle zwischen Kindergarten und Grundschule Ergotherapie. Die Statistik spricht von 13,2 Prozent aller 6-jährigen Jungen. Grund genug für uns, sich dem Vorschulkind auf dem ergotag stärker zu widmen. Hochkarätige Referenten beleuchten die potenziellen Schwierigkeiten der Kinder aus verschiedenen Perspektiven und zeigen Interventionsmöglichkeiten auf. Stöbern Sie in unserem Programm: Infos rund um die Veranstaltung finden Sie im Internet unter www.ergotage.de.

_ Dass sich der Übergang vom Kindergarten in die Schule bei manchen Kindern schwierig gestalten kann, ist uns allen bekannt. Hier können wir ansetzen - mit fundierten, gut durchdachten Konzepten, einer klientenzentrierten Befunderhebung und individuellen Therapieangeboten. Und auch mit präventiven Angeboten, Informationen und Beratung für Eltern, Erzieher und Grundschulpädagogen. Stellen Sie sich der Herausforderung und lassen Sie sich beim diesjährigen ergotag inspirieren!

Wir - das ergopraxis-Team und der Fachkreis Pädiatrie - freuen uns auf Sie! Ihre

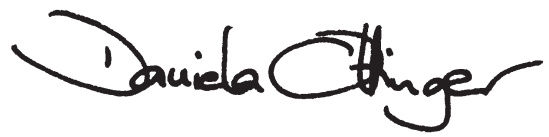

PS: Neugierig geworden und am 3. Oktober noch nichts vor? Dann würde ich mich freuen, Sie bei uns begrüßen zu dürfen!

\section{ZU GEWINNEN}

Kursplatz

2-tägiger Kurs „Interaktionsdiagnostik zwischen Mutter und Kind"

Bücher

5-mal „Supergute Tage oder Die sonderbare Welt des Christopher Boone“

Und außerdem ...

2-mal „Glücksbringer“ (Live-DVD)

5-mal je ein Karabiner

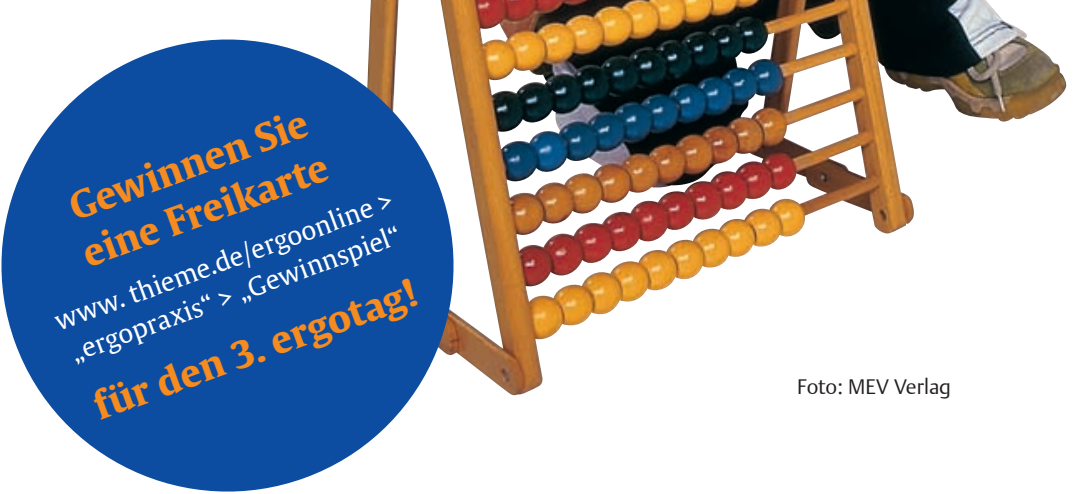

